\title{
DE PRAGA AO MUNDO ÁRABE: UMA ANÁLISE COMPARADA DE PRIMAVERAS POLÍTICAS
}

\section{From Prague to the Arab world: a comparative analysis of political springs}

Teresa Cristina Schneider Marques ${ }^{1}$ Antônio Eduardo Alves de Oliveira ${ }^{2}$

\section{Introdução}

A característica de renovação atribuída à primavera, estação que sucede o inverno e marca o início de um novo ciclo, fez com que os analistas chamassem de “primaveras” alguns dos mais importantes momentos de transformação política vividos pela sociedade. Dentre estes momentos, destacamos a Primavera de Praga de 1968 e a Primavera Árabe, que teve início em dezembro de 2010.

A Primavera de Praga está entre os movimentos de 1968 protagonizados pela juventude estudantil que evidenciaram o anseio pelo rompimento com os partidos tradicionais. Com a chegada ao poder de Alexandre Dubcekna Tchecoslováquia, comunista moderado, o país passa por uma reforma que ficou conhecida como Primavera de Praga por tentar conciliar a implementação de liberdades individuais com o sistema socialista. Para tanto, permitiu a criação de outros partidos políticos e pôs fim à censura, entre outras medidas (VAISSE, 2011, p.99).

Mais de quatro décadas depois, uma nova primavera marca o cenário político mundial, desta vez no mundo árabe. O estopim da revolta popular se deu na Tunísia, em

\footnotetext{
${ }^{1}$ Doutora em Ciência Política pela UFRGS, com estágio doutoral em relações internacionais Institut d'Études Politiques de Paris (Sciences Po). Bolsista de pós-doutorado (DOC-FIX) CAPES/FAPERGS PUC-RS. E-mail: teresacsm@gmail.com.

${ }^{2}$ Doutor em Ciências Sociais pela UFBA, com estágio doutoral em Relações Internacionais no Institut d'Études Politiques de Paris (Sciences Po). Professor adjunto da Universidade Federal do Recôncavo Baiano (UFRB). E-mail: antonioeduardo29@hotmail.com
} 


\section{Conjuntura Austral}

dezembro de 2010, após o jovem Mohamed Bouazizi atear fogo ao próprio corpo como protesto. O jovem Bouazizi, que estava desempregado e trabalhava como vendedor ambulante em SidiBouzid, se revoltou após a polícia apreender a mercadoria que ele vendia. Depois das manifestações se iniciarem na Tunísia ${ }^{3}$, produziu-se um efeito cascata provocando uma onda de protestos no Egito, na Argélia, no Iêmen, na Líbia, na Síria e na Jordânia, tendo um profundo impacto em todo mundo árabe e no Oriente Médio.

Após quase dois anos, os acontecimentos revolucionários que derrubaram governos, ainda hoje continuam a promover importantes manifestações nos países árabes.Diante desse fato e da repercussão política das duas primaveras, este artigo busca discutir, ainda que de maneira sucinta, alguns aspectos relativos às chamadas Primavera de Praga e Primavera Árabe.Ambos os movimentos representaram um desejo da sociedade civil de ruptura com o status quo; entretanto, ocorreram em momentos e contextos completamente distintos.

Recorremos, pois, à abordagem comparada, um dos principais métodos de pesquisa utilizados pelas ciências sociais para compreender os processos políticos. Alinhamo-nos a Sartori ao afirmar que a comparação, tendo como base o modelo do estudo de caso, pode possibilitar uma descrição mais detalhada das entidades, além de permitir identificar "leis de tendências” (SARTORI, 1994, p.06).

Assim, procede-se uma análise comparada das primaveras de Praga e do mundo Árabe, objetivando analisar os contextos políticos, os atores e as formas de ação adotadas. Esperamos verificar as similitudes e as diferenças entre os dois movimentos para compreendermos melhor o significado das manifestações, bem como analisarmos o papel da sociedade civil em cenário internacional cada vez mais marcado pelo transnacionalismo.

\footnotetext{
${ }^{3}$ A república Tunisina, mais conhecida como Tunísia, é um país do Norte da África. Está localizada na região do Magreb que, por sua vez, abrange, além da Tunísia, Marrocos, Sahara Ocidental, Argélia, Mauritânia e Líbia. Geograficamente, é a área do mundo árabe mais próxima do Ocidente.
} 


\section{Conjuntura Austral}

\section{A Primavera de Praga e o despertar da juventude}

Durante os anos 1960, a União Soviética (URSS) enfrentou um momento de estagnação econômica e de diminuição da sua influência política. Diante da diminuição do ritmo de desenvolvimento, devido aos seus problemas na produção agrícola e de bens de consumo, a população dos países da chamada “cortina de ferro" passaram a reivindicar a modernização econômica e social da região. O modelo soviético passou a ser contestado e aspirações liberais ganharam força (VAÏSSE, 2011 p.94).

O leste europeu foi uma das regiões sob influência soviética em que essa demanda pelo distanciamento da URSS ganhou força. Na Iugoslávia, as divisões nacionalistas marcaram a situação política do país, tanto interna como externamente. Apenas a presidência de Josip Broz Tito foi capaz de conter os movimentos separatistas que se fortaleceram com a participação da juventude, inspirada na contestação estudantil crescente no ocidente.

Na Hungria, por sua vez, o combate foi mais violento. Sob a liderança do moderado Imre Nagy, o sistema húngaro representou uma preocupação para os soviéticos, principalmente após anunciar sua saída do pacto de Varsóvia ${ }^{4}$. As tropas da URSS invadiram brutalmente o país em 1956 e a imagem do comunismo soviético começou a ser manchada (LOHBAUER, 2005, 1989). Além da Iugoslávia e da Hungria, a Polônia e a Romênia estão entre os países da região que enfrentaram a URSS, comandada por Leonid Brejnev durante a década de 1960.

Assim como na Iugoslávia, a participação de trabalhadores e estudantes é um aspecto notável nestes movimentos de contestação.A participação estudantil também é um dos aspectos mais relevantes do movimento de contestação que ocorreu na Tchecoslováquia em 1968, que agiram, segundo Eric Hobsbawm, estimulados pelo grande levante estudantil de maio de 1968 na França (1995, p.293).

No entanto, alguns fatores diferenciam a Primavera de Praga. O primeiro deles é o fato da Tchecoslováquia estar passando por um momento de "liberalização" durante

\footnotetext{
${ }^{4}$ Também conhecido como Tratado de Varsóvia, o Pacto foi criado em 1955 e reunia a URSS e os países do Leste Europeu que se encontravam sob a influência soviética. Tratava-se de um acordo militar que, através de conselheiros e armamentos militares, possibilitou que a URSS controlasse os países que se encontravam na sua zona de influência (LOHBAUER, 2005, p. 183).
} 


\section{Conjuntura Austral}

a década de 1960. Diante da oposição do eslovaco Alexander Dubcek, Novotny se retirou do poder e, em março de 1968, Dubcek chegou ao posto de secretário do Partido Comunista e o General Jan Svoboda, ao cargo de chefe do Estado (LOHBAUER, 2005, p. 191).

A partir de então, a Tchecoslováquia passou a implementar um "programa de ação” que foi apoiado por grande parte da população, sobretudo por intelectuais e setores industriais, que exigiam a descentralização da economia visando a uma aproximação com o ocidente e a democratização (LOHBAUER, 2005, p. 191). Entre as medidas previstas pelo programa, podemos citar a reforma econômica, que procurava garantir maior autonomia às empresas tendo como base o modelo da autogestão e a diversificação dos parceiros comerciais internacionais (BROUÈ, 1979). Porém, merece grande destaque a reforma política, que previa a reorganização do partido e autorizava a existência de pequenos partidos, entre outras medidas que permitiriam a ampliação e garantia de liberdades civis (REIS e MORAES, p.49).

As reformas não significavam um rompimento brusco com a URSS. Pontos considerados chave pelos soviéticos, tais como o fim da propriedade privada e a participação da Tchecoslováquia no Pacto de Varsóvia, não foram colocados em questão por Dubcek. Sua intenção era alcançar um “socialismo com face humana” ou, em outras palavras, conciliar o socialismo com medidas liberalizantes. As reformas conseguiram apoio não apenas internamente, mas inclusive no plano externo, dentre os quais podemos citar a Iugoslávia de Tito (SOUTOU, 2010).

A Primavera de Praga, portanto, ainda que não solicitasse um rompimento brusco com a URSS, está relacionada a uma demanda da sua população por participação no processo de decisão política. Apesar do caráter moderado do "programa de ação” e do apoio interno e externo por ele alcançado, o movimento não agradou a União Soviética, causando uma crise no relacionamento desta com a Tchecoslováquia. Temiase que as reformas se estendessem aos outros países do leste europeu e que ameaçassem o papel central desempenhado pelo partido no Estado e na sociedade. Gradualmente, a URSS passou a aumentar as pressões sobre a Tchecoslováquia. 


\section{Conjuntura Austral}

Dubeck se recusou a ceder às pressões dos dirigentes do Pacto de Varsóvia, e no dia 21 de agosto de 1968 as tropas de cinco países do Pacto de Varsóvia - URSS, Alemanha do Leste, Polônia, Hungria e Bulgária - invadiram Praga em massa (VAÏSSE, 2011, p. 97). As tropas enfrentaram a resistência pacífica da população tcheca que se organizou em torno do presidente da República, Svoboda, e de Dubeck, secretário do partido comunista.

A resistência, protagonizada pela juventude tcheca que se organizou através de informações trocadas pelo rádio, é um dos aspectos mais interessantes da Primavera de Praga. Além da troca e das modificações de placas com nomes de ruas visando confundir as tropas, uma greve geral decidida em uma reunião clandestina do partido teve início no dia 23 de agosto. É significativo o caso de Jan Palach, um estudante de 20 anos que se suicidou em janeiro de 1969 em Praga, ateando fogo no próprio corpo em protesto contra a invasão soviética. Embora a maior parte dos manifestantes tenha seguido as diretrizes dos dirigentes Tchecos de resistir pacificamente, houveram "reações dispersas e desesperadas" (REIS e MORAES, p.50). No total, 20 manifestantes foram mortos e 300 ficaram feridos durante a Primavera de Praga.

Do ponto de vista militar, a invasão conseguiu atingir os seus objetivos, haja vista que praticamente não enfrentou resistência armada e, em pouco tempo, havia concluído a invasão. Os representantes tchecos foram presos e levados a Moscou, e os manifestantes derrotados pelas tropas. Em abril de 1969, Dubcek foi substituído por Gustav Husak e gradualmente o modelo político e econômico soviético foi reimplantado no país. Com a criação da “doutrina Brejnev”, em 1968, os soviéticos esperavam limitar a soberania dos países da cortina de ferro e legitimar a invasão soviética em países onde eventualmente se posicionassem de maneira contrária à URSS (SOUTOU, 2010, p. 687).

Porém, do ponto de vista político, os efeitos do enfretamento foram extremamente negativos para a imagem do sistema soviético, mais ainda do que a crise com a Hungria anos antes. Isso ficou claro com o pronunciamento contrário à invasão feito pela Romênia - que fazia parte do Pacto de Varsóvia -, com a retirada da Albânia do Pacto em setembro de 1968 e com os protestos de dezenas de intelectuais em 


\section{Conjuntura Austral}

Moscou. Para os países comunistas, a violenta intervenção das tropas soviéticas em Praga representou o fim da esperança em um "socialismo com rosto humano" (SOUTOU, 2010, p. 682). Nos países do bloco ocidental, a ausência de liberdade e a violência do sistema soviético se tornaram evidentes, prejudicando definitivamente a ideologia comunista e dando espaço para uma crescente valorização da democracia.

Nota-se, dessa forma, que a Primavera de Praga foi uma mobilização nacional que teve um impacto transnacional. Isto é, influenciou atores não-estatais em outros países e regiões. Embora o movimento tenha sido derrotado, ele representou uma transformação da posição soviética em um contexto ainda marcado pela Guerra Fria e apontou para novas formas de participação política. Assim como os demais acontecimentos que marcaram o ano de 1968, também se destaca por ter evidenciado o importante papel a ser desempenhado por atores políticos não estatais - sobretudo a juventude - nas transformações políticas e sociais. Veremos que muitos desses aspectos também são perceptíveis ao analisarmos a Primavera Árabe que teve início em dezembro de 2010.

\section{A Primavera Árabe e a renovação da articulação política}

Mais de 40 anos após a Primavera de Praga, o contexto mundial é totalmente distinto. Não há mais a divisão ideológica que marcou a Guerra Fria; no ocidente, predominam os sistemas democráticos. Entretanto, na África e no Oriente Médiomuitos países viviam décadas de regimes autoritários, até que um jovem desempregado se suicidou na Tunísia da mesma forma que Jan Palach havia feito em Praga 42 anos antes.

Seu suicídio, em dezembro de 2010, sensibilizou a população e a incentivou a se mobilizar contra o status quo, tornando-se o estopim de uma onda de revoltas populares que se espalhou por diversos países da região e ficou conhecida como Primavera Árabe. No entanto, segundo Alexandre Roche é importante destacar que os acontecimentos na Tunísia, no Egito, na Síria, no Marrocos, na Argélia, na Líbia, no Sudão - do Norte -, nos territórios palestinos, da Jordânia, do Líbano, da Síria, do Iraque, de Omã, do Iêmen, dos Emirados e da Arábia Saudita evidenciam a relação existente entre os fatores políticos,econômicos, sociais e culturais (ROCHE, 2011, 


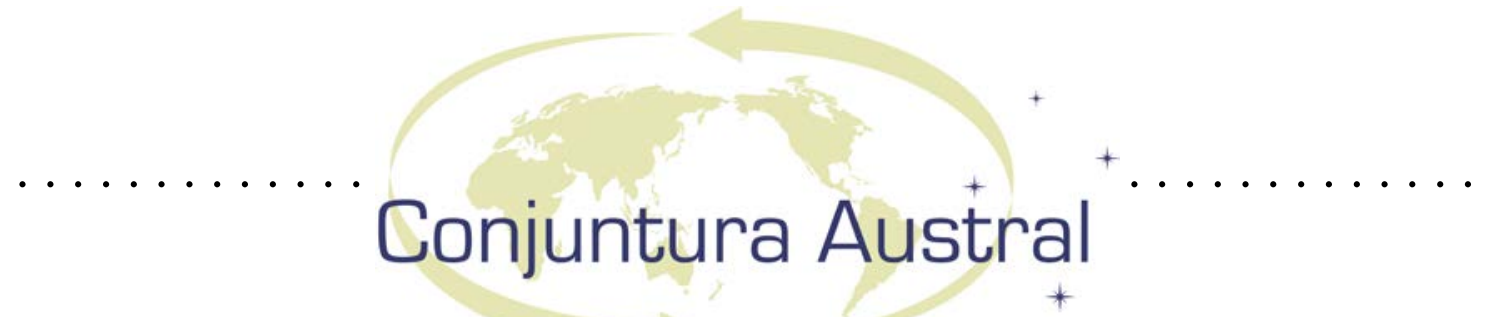

p.03). A análise da relação entre todos esses fatores com a crise capitalista mundial nos ajudam a compreender a derrubada dos governos na Tunísia, no Egito, na Líbia e nos demais países da região.

Na Tunísia, onde a Primavera eclodiu, o ato desesperado de Mohamed Bouazizi trouxe à superfície o descontentamento da sociedade com os rumos do regime liderado por Zine El Abdine Ben Ali, que dirigia o país havia 23 anos. Ben Ali instaurou um modelo de ditadura que é um dos pilares de sustentação dos interesses das grandes potências na região. A revolução na Tunísia colocou em relevo a profunda fraqueza estrutural dos regimes autoritários do mundo árabe.

Por sua vez, no Egito os manifestantes pediam o fim do governo Mubarak e o fim da tortura, da pobreza, do aumento do preço dos alimentos, o fim da corrupção e do desemprego - reivindicações muito semelhantes às dos trabalhadores e estudantes que se levantaram na Tunísia (KEMPF, 2011). Utilizando as novas redes sociais tais como Twiter e facebook para organizar os protestos que visavam sensibilizar a opinião pública internacional, os manifestastes conseguiram afastar Mubarak do poder após 30 anos de ditadura.

Além da derrubada dos governos na Tunísia e no Egito, verificou-se amplos movimentos de revolta na Síria, no Iêmen e na Líbia. Enquanto esses países se viram mergulhados em verdadeiras guerras civis, o Líbano, a Jordânia, os territórios palestinos, o Iraque, o Kuwait, Emirados, Omã, Arábia Saudita, Sudão (Norte), Argélia, Marrocos também assistiram o crescimento das revoltas, ainda que estas não tenham evoluído da mesma maneira que se deu em países como a Tunísia, o Egito ou a Líbia (ROCHE, 2011, p.13).

A mobilização nos países árabes está relacionada com a insatisfação contra regimes políticos que impossibilitavam a participação popular. Nesse sentido, as reivindicações democráticas emergiram como elemento catalisador da insatisfação com a precariedade das condições de vida dos trabalhadores, em especial dos jovens. Esse quadro fez com que os jovens dos países árabes adotassem um posicionamento político que pode ser considerado laico e cosmopolita (ROCHE, 2011, p.03). 


\section{Conjuntura Austral}

Com efeito, os acontecimentos mencionados colocaram em evidência o colapso dos regimes nacionalistas árabes. Os primórdios do movimento nacionalista nos países árabes no século XX foram as convulsões contra a dominação turca e a luta contra os ingleses, italianos e franceses. O Egito, por exemplo, conseguiu sua independência formal em 1922, mas foi com a chegada ao poder de Gamal Abdel Nasser,em 1952, derrubando o rei Farouk, que o nacionalismo árabe ganhou a sua principal expressão, tendo a nacionalização do canal de Suez, em 1956, como acontecimento símbolo (KEMPF, 2011).

Após o fim do colonialismo europeu, uma burguesia nacionalista emergiu com a exploração do petróleo. Essa burguesia nacional procurou estabelecer limites à exploração das grandes potências através da formulação de um programa de independência e desenvolvimento. Com o objetivo de conquistar o apoio da classe operária e agrária, algumas concessões foram realizadas, dentre as quais podemos destacar a nacionalização de certos setores da economia.

Entretanto, os governos de Muamar al-Kadafi na Líbia e do herdeiro de Sadat e Nasser, Hosni Mubarak, no Egito, se converteram em adeptos de reformas neoliberais que mantiveram as condições de dominação na última década. Tais reformas enfraqueceram progressivamente as fronteiras e as regulações nacionais. Além disso, a formação e manutenção de ditaduras também facilitaram o processo, na medida em que limitaram as possibilidades de dar voz aos múltiplos atores. Percebe-se dessa forma que os regimes procuraram se adaptar aos interesses das grandes potências mundiais (COSTA, 2011, p. 22). As reformas neoliberais, porém, estavam longe de resolver os problemas enfrentados pela população, haja vista que não acompanharam o desenvolvimento da crise capitalista mundial e das contradições internas nesses países.

Assim, o aparecimento das manifestações gigantescas nos países árabes evidencia o fracasso dos regimes autoritários na região, liderados por elites corruptas e marcados pelas reformas neoliberais. Alguns aspectos das mobilizações que compõem a Primavera Árabe merecem ser destacados.

Um primeiro aspecto relevante é a participação cidadã, sobretudo da juventude estudantil em estados de tradição islâmica, cujos temas são inéditos para o campo de 


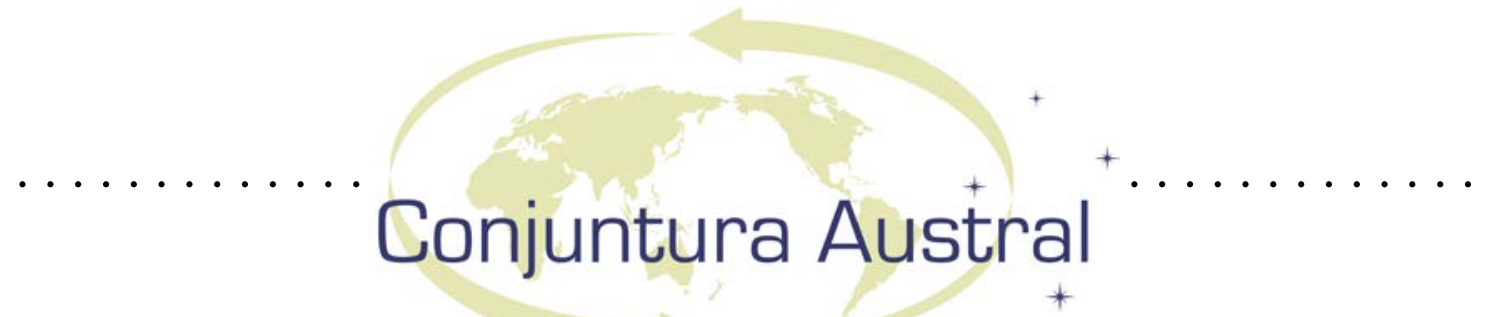

estudo da sociologia, da política e das relações internacionais. O papel inovador e antisistêmico dos movimentos juvenis pode ser notado na Primavera Árabe da mesma forma como foi notado na Primavera de Praga, em especial no estopim das manifestações na Tunísia e no Egito. A derrubada de governos na Tunísia, no Egito e na Líbia, com enfraquecimento de outros governos, como na Síria, têm evidenciado a participação política de amplos setores sociais, em especial os jovens, e das mulheres, nas recentes mobilizações no Egito.

Outro aspecto a ser destacado são as novas formas de articulação social, como a utilização das redes sociais para construir redes de mobilizações sociais que demonstram a transformação das estratégias de combate político. Tal transformação é perceptível sobretudo quando analisamos o alcance das ações propiciado pela rapidez dos meios de comunicações atuais. Porém, as passeatas, manifestações e o sacrifício do corpo visando sensibilizar a opinião pública se mantiveram no repertório de ação da juventude árabe.

Também é notável que os movimentos de contestação tenham afetado os equilíbrios regionais e internacionais. Os acontecimentos da Primavera Árabe destacam-se pelo fato de seu processo ter levado à formação de uma mobilização nacional com um impacto transnacional, que influencioua África do Norte eo Oriente Médioe fez com que as atenções do mundo inteiro se voltassem para a região.

Assim, merecem destaque o alcance e a repercussão das mobilizações nos países árabes. As mobilizações se espalharam e agravam as contradições do espaço mundial, em especial a configuração tradicional que coloca os países do mundo árabe como países sem sociedade civil, com populações conformadas com sistemas autocráticos e, portanto, sem legitimidade para uma participação mais efetiva no mundo contemporâneo. Como salienta Samir Amim (2011), a compreensão dos acontecimentos de 2011 é obscurecida por preconceitos e generalizações sobre o “mundo árabe”.

A erupção das mobilizações nos países árabes apresenta um evidente caráter espetacular e inovador, independente dos resultados a serem alcançados no futuro próximo. Eles representam uma importante ruptura não somente com o tradicionalismo 


\section{Conjuntura Austral}

estabelecido nos países de orientação mulçumana, mas inclusive com a ordem internacional.

\section{Considerações finais: diferenças e similitudes}

Ao possibilitar verificar as diferenças e as características compartilhadas entre as duas primaveras políticas, o método comparativo se mostrou com uma possibilidade teórica para a compreensão de fenômenos dessa natureza, marcados pela falta de previsibilidade. Se as características políticas, sociais, econômicas e culturais dos contextos nos quais se desenvolveram os fenômenos aqui em análise apresentam profundas diferenças, ao analisar os atores, as formas de ação e os objetivos e alcances dos dois movimentos, percebemos diversos pontos em comum.

A Primavera de Praga teve como pano de fundo a Guerra Fria, que passava pelo período da Détente, e uma crise de relacionamento da URSS com diversos países da chamada cortina de ferro. A estagnação econômica e o anseio por um socialismo que fornecesse canais de participação política incentivaram o governo da Tchecoslováquia a aprovar um pacote de reformas que desagradou os soviéticos. No mundo árabe, por sua vez, as ditaduras predominavam mesmo em um contexto internacional de crescente valorização da democracia. A ausência de canais de participação política e as desigualdades sociais causadas pelas reformas neoliberais incentivaram a população a se mobilizar contra os governos autoritários. Dessa forma, notamos que ambas as revoltas estão relacionadas a uma demanda da população civil por participação nos processos de tomada de decisão política.

É notável, ainda, o caráter transnacional de ambos os movimentos. Protagonizados pela população civil, as duas primaveras políticas em análise encontraram ecos nos países vizinhos e muito embora não tenham modificado de fato o equilíbrio de poder, representaram momentos de impacto para a ordem internacional existente. A Primavera de Praga, ainda que seja considerada um fracasso por muitos analistas por não ter conseguido pôr fim à invasão soviética, representou uma grande perda de prestígio para URSS, não apenas nos países da chamada cortina de ferro, mas inclusive no ocidente. 


\section{Conjuntura Austral}

Quanto à Primavera Árabe, as novas formas de intervenção popular abertas pela revolta trouxeram esperanças de que as demandas democráticas poderiam trazer modificações nos países em questão. Entretanto, o desenrolar do quadro político e social no Egito e outros países da região chegou a desapontaralguns analistas otimistas, fazendo com que a possibilidade de que este fenômeno possa vir a ter o mesmo fim que a Primavera de Praga tenha sido cogitada. Porém, no caso do Egito, a resposta do governo diante dos protestos da população, ao revogar decretos presidenciais, indica que um caminho diferente ainda pode ser possível para a Primavera Árabe.

Avaliamos a Primavera Árabe da mesma forma que Daniel Aarão Reis e Pedro de Moraes avaliaram o Maio Francês e a Primavera de Praga: movimentos que cresceram muito rapidamente e que por isso, não desaparecem rapidamente (REIS E MORAES, p.51). De qualquer forma, ainda que a Primavera Árabe tenha o mesmo fim que a Primavera de Praga, a queda dos governos ditatoriais são sintomas relevantes da nova era no espaço mundial, com o enfraquecimento do poderio das potências tradicionais - como os Estados Unidos - na região (GRESH, 2011).

Dessa forma, ambos os movimentos comprovam que, diante do avanço dos meios de comunicação, a sociedade mundial não pode ser compreendida apenas como um conjunto de Estados-Nações, e sim como uma sociedade transnacional, na qual interagem forças sociais, políticas e econômicas não estatais, além de diferentes sistemas nacionais (Cf. KAISER, 1971, p.801-802).

Porém, dentre todos os aspectos compartilhados pela Primavera de Praga e a Primavera Árabe, convém destacar o papel protagonista desempenhado pela juventude, sobretudo estudantil. Na sociedade contemporânea, a juventude tem assumido um papel inovador, não somente pela sua forma de atuação, mas também por influenciar mudanças no nível da cultura política, abrindo novos espaços para a contestação da estrutura social existente.

O papel inovador da juventude é perceptível em ambos os movimentos. Tanto a juventude tcheca quanto a juventude árabe catalisaram a insatisfação da população dos seus países com governos autoritários. Utilizando-se dos meios de comunicação, renovaram as formas de combate às forças políticas no poder. A juventude tcheca 


\section{Conjuntura Austral}

utilizou-se dos rádios para encontrar formas não violentas de combate às forças soviéticas, negando o uso de armas defendido pelos partidos de esquerda tradicionais do período. A juventude Árabe, por sua vez, inovou ao utilizar os novos meios de comunicação para construir redes de mobilizações sociais. Por outro lado, ao analisar a revolta árabe, verifica-se a manutenção de formas de ação usadas pelos tchecos que visavam sensibilizar a opinião pública e do uso do corpo como um instrumento de luta política.

Ao comparar a Primavera Árabe com os movimentos que compuseram a chamada "Primavera dos Povos" de 1848, o historiador Eric Hobsbawmem entrevista à BBC também destacou o papel desempenhado pela classe média e pela juventude estudantil. Para o historiador, “as mais eficazes mobilizações populares são aquelas que começam a partir da nova classe média modernizada e, particularmente, a partir de um enorme corpo estudantil” (WHITEHEAD, 2011).

Portanto, a análise comparada das duas primaveras nos aponta para o importante papel político a ser desempenhado pela juventude, em todas as sociedades, independentemente do contexto político e econômico. O desabrochar da condição jovem, em uma sociedade em crise, potencializa os jovens enquanto catalisadores da insatisfação social. Estes, com o avanço dos meios de comunicação, transformam-se em um movimento que interage com outros agrupamentos, construindo laços diversos no interior da sociedade civil e renovando as formas de mobilização política.

Ainda que a Primavera de Praga não tenha obtido sucesso no seu objetivo de por fim a invasão soviética e embora os resultados a serem alcançados futuramente pelos países árabes ainda não possam ser mensurados, o caráter espetacular e inovador de ambos os movimentos é evidente. Além de destacar a participação de atores nãoestatais no cenário internacional, eles representaram uma importante modificação do equilíbrio de poder regional. 


\section{Conjuntura Austral}

\section{REFERÊNCIAS}

AMIM, Samir. 2011: Le printemps arabe? Mouvements, $n^{\circ}$ 67, 03/2011.

BROUÈ, Pierre. A primavera dos povos começa em Praga. São Paulo: Kairós, 1979.

COSTA, Renatho. Mais uma primavera histórica, os árabes plantam flores no deserto. Revista Conjuntura Austral. Vol. 2, nº. 5, Abr.Mai, 2011.

GRESH, Alain. Em busca da soberania: O que muda com o despertar árabe. Le Monde Diplomatique. 14 de setembro de 2011. Disponível em: $<$ https://www.diplomatique.org.br/edicoes_especiais_artigo.php?id=34>. Acesso em 20/12/2011.

HOBSBAWM, Eric. A era dos extremos: o breve século XX - 1914-1991. São Paulo: Companhia das Letras, 1995.

KAISER, Karl. Transnational Politics: toward a Theory of Multinational Politics. International Organization, v. 25, 1971.

KEMPF, Raphael. Revolução social? Raízes operárias da revolta egípcia. Le Monde Diplomatique. 14 de setembro de 2011. Disponível em: $<$ http://www.diplomatique.org.br/edicoes_especiais_artigo.php?id=38>. Acesso em: 20 dezembro 2011.

LOHBAUER, Christian. História das Relações Internacionais II: O Século XX - do declínio europeu à Era Global. Petrópolis-RJ: Vozes, 2005.

REIS, Daniel Aarão; MORAES, Pedro de. 1968: a paixão de uma utopia. $3^{a}$ Edição revisada e atualizada. Rio de Janeiro: Editora FGV, 2008.

ROCHE, Alexandre A. E. Primavera do mundo árabe-sunita: O Islã Árabe-Sunita entre o Wahhabismo conservador e o espírito crítico, entre a política do petróleo e a independência econômica. Revista Conjuntura Austral. Vol. 2, nº. 7; Ago.Set, 2011.

SARTORI, Giovanni. Bien comparer, mal comparer. Revue Internationale de Politique Comparée. Bruxelles, vol. 1, nº 1, p.19-36, 1994.

SOUTOU, Georges-Henri. La Guerre Froide: 1943-1990. Paris : Librarie Arthème Fayard/Pluriel, 2010.

VAÏSSE, Maurice. Les relations internationales depuis 1945. $12^{\mathrm{a}}$ Edição. Paris: Armand Colin, 2011. 


\section{Conjuntura Austral}

WHITEHEAD, Andrew. Para Hobsbawm, o protagonismo da classe média marca revoltas de 2011. $B B C$ Brasil.23 de dezembro de 2011. Disponível em: $<$ http://www.bbc.co.uk/portuguese/noticias/2011/12/111223_hobbsbawm_2011_classe_ media_bg.shtml>. Acesso em 05/01/2012.

Artigo recebido dia 31 de outubro de 2012. Aprovado em 03 de abril de 2012. 


\title{
Conjuntura Austral
}

\section{RESUMO}

A Primavera de Praga de 1968 marcou o contexto político mundial assim como a primavera árabe que emergiu mais de quatro décadas depois. Quase dois anos após o início das revoltas no mundo árabe, o presente artigo objetiva analisar os dois movimentos a partir da metodologia comparada. Dessa forma, espera-se compreender melhor o significado das manifestações, além de verificar o papel da sociedade civil no cenário internacional.

\section{PALAVRAS-CHAVE}

Primavera de Praga; Primavera Árabe; Sociedade Civil.

\begin{abstract}
The Prague Spring of 1968 marked the political world as the Arab spring that emerged more than four decades after. Almost two years after the start of the revolts in the Arab world, this article aims to analyze the two movements with the comparative methodology. Thus, we expect to better understand the meaning of the events, in addition to verify the role of civil society in the international scene.
\end{abstract}

\section{KEYWORDS}

Prague Spring; Arab Spring; Civil Society. 